\title{
The Problem of AIDS May Have Already Solved
}

\author{
Sergey Makarov \\ Independent Researcher, Riga, Latvia \\ Email: segrim@bas.lv
}

Received 10 September 2014; revised 8 October 2014; accepted 3 November 2014

Copyright (C) 2014 by author and Scientific Research Publishing Inc.

This work is licensed under the Creative Commons Attribution International License (CC BY). http://creativecommons.org/licenses/by/4.0/

c) (†) Open Access

\section{Abstract}

This article describes an alternative approach to the problem of AIDS. The author proposes a new theory. In this theory, HIV is not a "classic virus", but a parasitic program that does not have a material carrier.

\section{Keywords}

\section{AIDS, HIV, Immune Deficiency, Parasitic Program, Lymphocytes, Hyperthermia}

\section{Introduction}

In 1989, I set myself the task of finding a means of fighting AIDS. In solving any problem, I always try "to start all from the beginning". I'll explain it: the scientific and popular scientific literature "sin" is that many of the findings, conclusions and assertions often copied from one article to another without their checking and critical rethinking. In this case, all the errors and inaccuracies begin to multiply exponentially.

Very rare we meet the scholars who in his article are capable of, “to describe the bare facts” (observations), and end the article with the recognition that the scientific explanation of the observed phenomena they do not know. However, for the successful promotion of science forward namely such an article have a much higher importance than an article, in which to the author to the very beginning of the "all clear"... In short, I am working under the motto: "You should look for the beginning of everything and you will understand much!"

\section{The Search for the Origins of the Problem}

To solve my problem I began to analyze the macro-parameters that characterize AIDS. In this issue a huge help to me provided the article of Academician of the USSR Academy of Medical Sciences V. M. Zhdanov [1]. From this article I wrote 23 elementary messages (in the logical sense of the word) on the internal manifestations of 
AIDS, and 33 elementary messages on its external manifestations.

After the first phase of the logical processing of information (after the exception of tautologies, repetitions, after the using of generalizations) I still had 29 elementary messages. After the second stage of processing of information left me with only 9 messages. By eliminating the contradictions and by spending the deep logical analysis of the facts, I got the following conclusions:

1) The first man had contracted AIDS through sexual contact with a monkey.

2) HIV (human immunodeficiency virus) is missing in the semen.

3) HIV is usually transmitted with friction due to the mixing of live blood of two people (in the vagina or in the rectum).

4) HIV does not have the material carrier, it is not in the classic sense of "virus", it is a parasitic program.

5) The working of immune defense system consists NOT IN THE DESTRUCTION of alien viruses, bacteria, fungi, protozoa, etc. (as it is formally adopted), but IN BINDING them by means of the special program PID (program of immune defense of human) with specially produced by the organism lymphocytes, for example, T-helpers, followed by extracting the product of joining out of the human's body (e.g., in the form of diarrhea).

6) HIV uses the ability of T-helper cells to forming stable bonds, so it substitutes for the PID (program of immune defense of human), it connects the pairs of T-helper cells among themselves and sends them into the waste, as the result, the protection of the body becomes weakened.

\section{The Bases of the New Theory}

Conclusions, mentioned above, allowed me to draw the following diagrams (see Figure 1). The left diagram shows the working mechanism of the PID (program of immune defense of human). On the right one is shown the working mechanism of HIV parasitic program.

For HIV working in the body it does not have need in any input infections. HIV operates on the chain reaction principle ("domino effect"), this chain reaction from the periphery is moving closer and closer to the center, which generates new lymphocytes (in particular, to the thymus).

\section{The First Results}

So after the deciphering action scheme HIV, I became able to answer a number of issues on which earlier had no answers from professionals (see: [2]), such as:

\subsection{Why Do Some People Die of AIDS Quickly, While Others May Live for Decades?}

Answer. The binding lymphocytes by HIV, causes the body to their enhanced reproduction. If the rate of reproduction of lymphocytes greater than the rate of their "devouring" by HIV, if this excess of lymphocytes is sufficient to fight the input infections (infections, by the way, we get with every breath and in the eating of food),

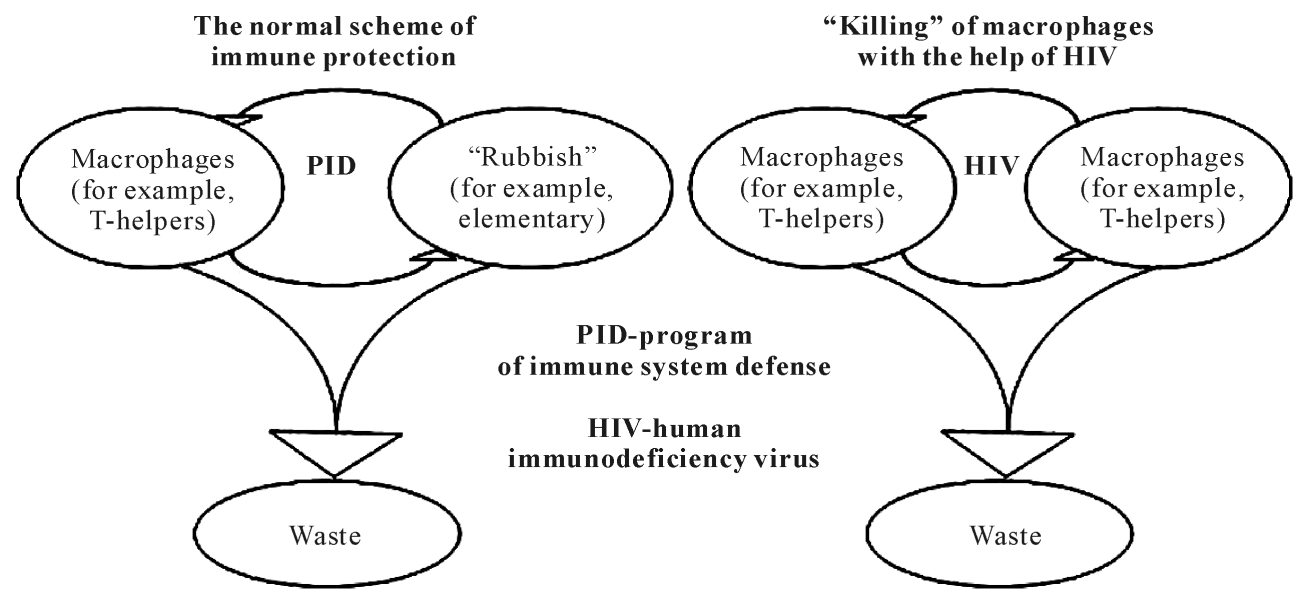

Figure 1. Diagrams of the working mechanisms of PID and HIV programs. (http://commons.wikimedia.org/wiki/File:1989_May_22.jpg) 
then the person can live a very long time. If the body is weak, the whole mass of lymphocytes is expended "to feed” HIV and there are no lymphocytes to deal with the input infections, so these infections are rapidly rendering the person into the grave.

\subsection{Why, of $100 \%$ of AIDS Patients Only $10 \%$ of Women?}

Answer. Man's sexual contact with a man is perverted. In this case, the genitals and the rectum are getting micro-traumas that result to a mixture of blood and, as a consequence, the transmission of AIDS contagion from one organism to another. Man's sexual contact with a woman usually has a natural form. Nature takes care of vagina lubrication to prevent genital sores, so if the man have sex with a woman (and there is a good lubricant!), AIDS is not transmitted due to the lack of mutual contacts live blood of partners.

\subsection{Why AIDS Is Transmitted through a Syringe and Is Not Transmitted by Mosquitoes?}

Answer. Blood is known to be able to remain for some time in the state of living tissue even outside the body (remember the blood transfusion), so the HIV in such blood for some time (up to the ending of lymphocytes) continues to "work". If such blood to enter to another person (accidentally or intentionally), HIV continues his "work" in a new organism. Unlike a syringe, blood-sucking insects are not just vessels: after they sucked the blood, they immediately begin to recycle it. While a mosquito made one bite till the time when the mosquito bites another person, the person's blood inside the mosquito is no already a proper quality live blood, so HIV is not saved in it.

If the HIV had a material carrier, this carrier from one bite till the next one would, in principle, remained viable within a mosquito. However, if HIV is working as the "domino effect", after binding of the last pair of T-helper cells in a small volume of blood this parasitic reaction must disappear by itself.

So what does all this imply? Firstly, if I became able to give answers to the questions which previously had no answers from professionals (see, for example, [2]), so the theory, which I have constructed, most likely, is true theory. Secondly, if the theory is correct, then namely on the base of this theory we need to seek a means to combat AIDS. How to do it? To answer this question, let's analyze the list of the earliest external manifestations of AIDS:

1) Diarrhea (joined to each other T-helper cells are rapidly eliminated from the body).

2) Decrease of body weight (this is a consequence of frequent diarrhea followed by dehydration of the body).

3) Swollen lymph nodes (glands of internal operation are activated for producing new protective antibodies to replace those that HIV is "reworked").

4) The sharp increase in body temperature.

In this the 4th paragraph we should elaborate. The idea that by means of the increasing of the temperature of the human body it resists against the disease, is not new. I also have no doubt in this situation. This question, however, requires analyzing the three moments:

- in which organs of the human's body and whether evenly the temperature rises,

- by means of which energy recourses the temperature moves up (are they sufficient?),

- till what level the temperature must be increased for the fighting against namely this specific disease.

\section{The Proposed Therapy}

If with the increasing the body temperature the organism counteracts the action of HIV, it is logical to assume the existence of a particular level of temperature at which the chain reaction HIV will stop. If HIV-the program (i.e., HIV has no material carrier), so being once stopped, this program will not be able to continue itself (remember the "domino effect"). For the program will not be able to continue itself after the removal of the temperature, we must warm up all the blood in man.

We know from history that the temperature in the diseased body of human can rise up to the mark of 43.5 degrees Celsius. Apparently, this is the limit of the possibility of natural increase in body temperature for the ordinary man.

I believe that in order to stop the chain reaction of AIDS will be enough 44 degrees Celsius, but we must heat the entire blood in human body.

The body of human normally raises its temperature by a variety of chemical reactions, and the starting ma- 
terial is a food consumed by human. Different people have different abilities to digest food. The same should be said about the ability of different people to tolerate high temperatures. However, anyone who's been in the sauna knows that even stay in the atmosphere heated up to 100 degrees Celsius and above does not lead to negative consequences for the organism. This is because, that in the sauna man warms only his outer shell, though —at a shallow depth. In the human body have vast natural abilities that protect its internal organs as from hypothermia, and from overheating. Therefore, when carrying out a treatment hyperthermia we will need to temporarily disable a natural mechanism that protects the internal organs of the body from overheating.

Many fear that such curative hyperthermia may cause coagulation of some proteins in human blood. I agree, that in this direction we need more research to prevent such a process. However, already carried out in this direction of studies to show that coagulation of protein requires a temperature higher than 44 degrees Celsius.

In my medical hyperthermia I'm talking about raising the body temperature up to 44 degrees Celsius up to 1 minute, but this temperature increase should take place throughout the body.

For such increase in temperature could bear any organism, it is necessary, probably, add one condition: for the rising of the body temperature the man should not expend its own energy. Is it possible? Yes, it is possible. Anyone who enjoyed local UHF-therapy knows that by this method the living tissues get warm without own energy costs. If to recollect the modern high frequency electric furnace, in which the high frequency field prepares food, proposed by me method of treatment becomes obvious, namely:

1) You need to create the camera to place in it a whole man and to create in its volume UHF field (frequency, apparently, is not very important, but first we must use the same frequency as in the UHF-therapy devices: 800 $1000 \mathrm{kHz}$ ).

2) Place the whole person into this camera.

3) By continuously increasing the intensity of the field to rise the man's body temperature up to 44 degrees Celsius and sustain the man at that temperature for about 1 minute (to avoid the "shadow zones" will be better if the person will do a bit moving in this camera). Method for temperature control of the body in such conditions is described, e.g., in [3].

4) Slowly lower the intensity of the field and release a healthy person.

\section{Further Development of the Method}

Apparently, in future the camera should be produced not as such closed box, but as a long open tube sizing in height of the man (as a magnetic ring at the airport), the length of a pipe-chamber must be selected experimentally. My idea is that a person is included into one end of a continuously running UHF tube and exits the other end thereof. More frail (painful) people will go through pipe slowly, more healthy—faster, i.e. while lasts their therapy at the camera, each man will spend on the elaboration of the body by the UHF field as much time as it is required for a concrete level of the health of his body.

It should add the following. While analyzing the sources of leukemia, multiple myeloma, diabetes, and other illnesses, I came to the conclusion that the reason of these and many other diseases is that the immune system of protection of a man or impairs work, or fully ceases to operate. It is logical to assume that in each of these cases in the work of the body interferes some parasitic program that does not have a material carrier, but has a considerable potential in the implementation of the parasitic chain reaction. This program you cannot see through a microscope, it is useless "drip on it from the pipette", so all the efforts of microbiologists and infectious disease specialists in dealing with such diseases are futile.

From this follows that for the above-mentioned diseases treatment should be the same. I have no doubt that these diseases a man also can self-treat with a biofield, including his own biofield, but such a treatment cannot do every man: the load on the body will be an enormous.

\section{A Few Words about the Priorities}

I want to note that the use of full hyperthermia to fight cancer has international priority-May 29, 1984, as it indicated by the work [4]. In the same article noted that cancer - a disease of the whole body, so using the local hyperthermia against it does not make sense. There's also indicated a positive difference of hyperthermia from all other types of therapy: hyperthermia is not toxic, it absolutely not cripples the body, as it happens, for example, while radiation exposure or chemotherapy. 
About 10 years ago, the fight against AIDS and cancer diseases was engaged in the Russian company "Shahatana" under the guidance of the President of the International Academy of New Medical Technologies in Russia Professor V. P. Chekurov. In their practice, for the treatment of AIDS and cancer diseases, this company, in particular, used the method of "optimal resonance hyperthermia", which has been namely the full-body hyperthermia. The using by this firm the full electromagnetic hyperthermia against cancer and AIDS has proved its effectiveness. Unfortunately, the Russian Ministry of Health subsequently completely banned the use of all types of full hyperthermia in Russia. After this the professor V. P. Chekurov left Russia and continued using his treatment method in Bulgaria. About the using of this therapy against cancer you can read in [5]. It remains to add that the method of "optimal resonance hyperthermia" was patented by Professor Chekurov only in 1999.

Now in Russia the therapy of AIDS by hyperthermia is applicable by Professor Suvernev A. V. in the Siberian Research Institute of hyperthermia (http://www.sibniig.su/). He patented his method with a priority of 5 May 1998 (see: [6]). I want to note that in his method hyperthermia is performed by immersing the patient in a hot water bath, but the head is not submerged. Despite numerous reports on the effectiveness of this therapy, it does not always lead to success, and can not be considered the "full body hyperthermia". About Suvernev's works you can read, for example, in his monograph [7].

Although Suvernev long been aware of my priority in the theory of the application of the method of full hyperthermia against AIDS, he just ignores it in all his publications.

Believe me, it is insulting to me at the XXI century to read some articles about AIDS (see, for example, [2]), in which people are seriously concerned about the search for answers to questions to which I replied yet in 1989. After all, about my results I immediately informed the four Academies of Sciences and several other organizations. But up to now many scientists are only intending to get closer to answering the question of why some people are dying of AIDS quickly, and the other HIV-positive people are living to 20 years or more.

\section{Conclusions}

In brief article, I cannot describe in detail the theoretical justification of the proposed by me method. Those interested English-speaking people can read the detailed justification at my monograph [8]. In the same monograph was made a thorough patent search with the proof of my global priority in the proposal of the method against AIDS as of May 1989. Russian-speaking readers could obtain the same information from my monograph [9], which was published in Russian.

I want to emphasize that my therapy does not kill anyone, it only disconnects early joined by the parasitic program pairs of T-helper cells, "give back to their mind" and sends them back to guard the body against input infections (if they are not have been removed from the body with diarrhea).

In this article, I used macro-approach to the analysis of the scientific issues, in contrast to the micro-approach, which is typically used by the microbiologists and by the infectious disease specialists. Perhaps AIDS is so unusual disease, that it just falls out of the activities scope of microbiologists and the infectious disease specialists, therefore this problem cannot be resolved by their methods for many years.

Shown above the approach to analyzing the properties of the system under the name of "human organism", the cyberneticians usually call as the "method of black-box testing".

\section{References}

[1] Zhdanov, V.M. (1987) AIDS: What Do We Know about Him? Health, 5, 6-7.

[2] Philipkoski, K. (2002) Why Some with HIV Are Healthier. http://www.wired.com/medtech/health/news/2002/09/55417

[3] Gibbs, F.A. (1983) “Thermal Mapping” in Experimental Cancer Treatment with Hyperthermia: Description and Use of Semi-Automatic System. International Journal of Radiation Oncology*Biology* Physics, 9, 1057-1063.

[4] Cole, D. (1984) Rethinking Cancer. Whole-Body Hyperthermia.

[5] Method of Optimal Resonance Hyperthermia. http://www.worder.org/ianmt/profilaktika/orgt.pdf

[6] Suvernev, A.V., Pisarev, A.A., Penjagin, A.N., Vereschagin, B.P. and Yefremov, A.V. (1999) Method of Whole Human Body Hyperthermia. ROSPATENT Patent No. 2126667.

[7] Suvernev, A.V., Ivanov, G.V., Novozhilov, S.Yu. and Yefremov, A.V. (2011) Intensive Hyperthermia Therapy. Academic Publishing House “GEO”. http://www.izdatgeo.ru 
[8] Makarov, S. (2012) Puzzle with the Name “AIDS”. LAP LAMBERT Academic Publishing, Hamburg, ISBN: 978-3659-23679-2.

[9] Makarov, S. (2012) Puzzle with the Name “AIDS”. LAP LAMBERT Academic Publishing, Hamburg, ISBN: 978-3659-17906-8. 
Scientific Research Publishing (SCIRP) is one of the largest Open Access journal publishers. It is currently publishing more than 200 open access, online, peer-reviewed journals covering a wide range of academic disciplines. SCIRP serves the worldwide academic communities and contributes to the progress and application of science with its publication.

Other selected journals from SCIRP are listed as below. Submit your manuscript to us via either submit@scirp.org or Online Submission Portal.
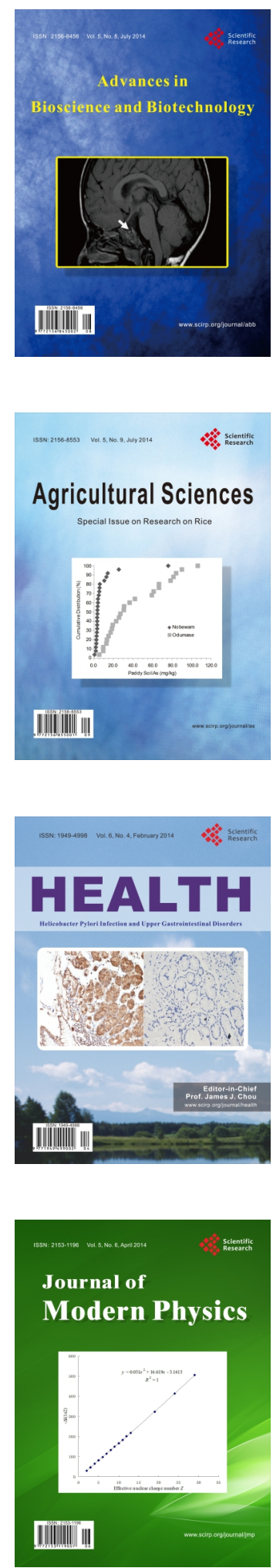
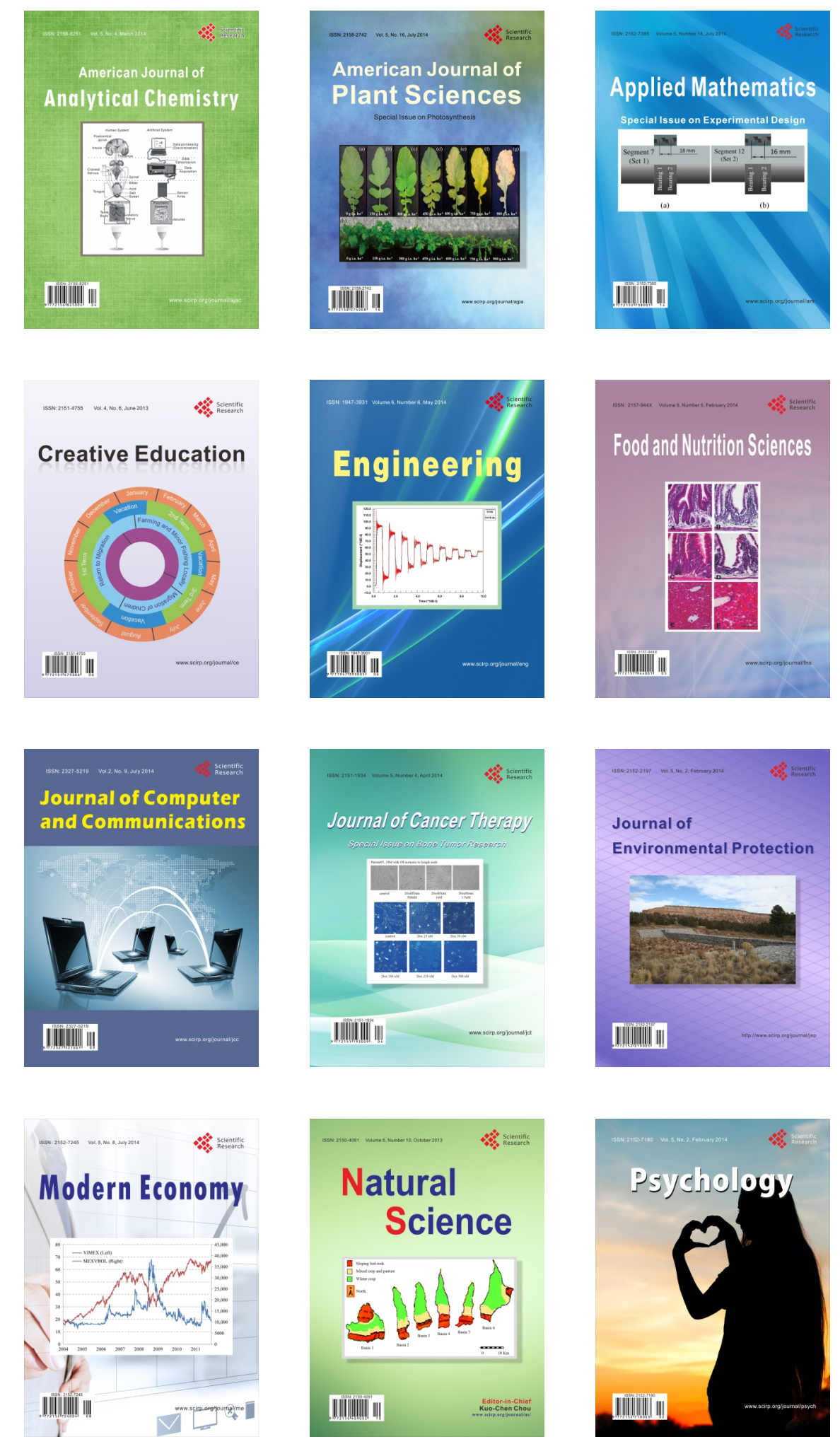